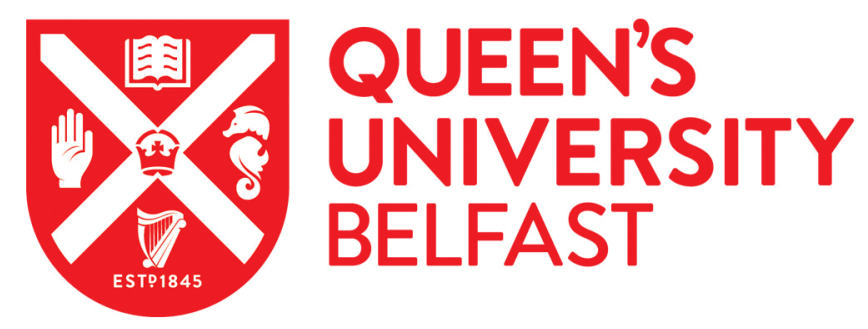

\title{
Helicobacter Pylori Infection is Associated With Reduced Risk of Barrett's Esophagus: An Analysis of the Barrett's and Esophageal Adenocarcinoma Consortium
}

Wang, Z., Shaheen, N. J., Whiteman, D. C., Anderson, L. A., Vaughan, T. L., Corley, D. A., El-Serag, H. B., Rubenstein, J., \& Thrift, A. P. (2018). Helicobacter Pylori Infection is Associated With Reduced Risk of Barrett's Esophagus: An Analysis of the Barrett's and Esophageal Adenocarcinoma Consortium. American Journal of Gastroenterology. https://doi.org/10.1038/s41395-018-0070-3

Published in:

American Journal of Gastroenterology

Document Version:

Peer reviewed version

Queen's University Belfast - Research Portal:

Link to publication record in Queen's University Belfast Research Portal

\section{Publisher rights}

(C) 2018 by the American College of Gastroenterology. This work is made available online in accordance with the publisher's policies. Please refer to any applicable terms of use of the publisher.

\section{General rights}

Copyright for the publications made accessible via the Queen's University Belfast Research Portal is retained by the author(s) and / or other copyright owners and it is a condition of accessing these publications that users recognise and abide by the legal requirements associated with these rights.

Take down policy

The Research Portal is Queen's institutional repository that provides access to Queen's research output. Every effort has been made to ensure that content in the Research Portal does not infringe any person's rights, or applicable UK laws. If you discover content in the

Research Portal that you believe breaches copyright or violates any law, please contact openaccess@qub.ac.uk. 
Helicobacter Pylori Infection is Associated With Reduced Risk of Barrett's Esophagus: An Analysis of the Barrett's and Esophageal Adenocarcinoma Consortium

Short title: Helicobacter pylori and risk of Barrett's esophagus

Zhensheng Wang, MPH, PhD, ${ }^{1}$ Nicholas J. Shaheen, $\mathrm{MD}, \mathrm{MPH},{ }^{2}$ David C. Whiteman, MBBS, PhD, ${ }^{3}$ Lesley A. Anderson, PhD, MPH, ${ }^{4}$ Thomas L. Vaughan, MD, MPH, ${ }^{5}$ Douglas A. Corley, MD, PHD, ${ }^{6,7}$ Hashem B. El-Serag, MD, MPH, ${ }^{8,9}$ Joel H. Rubenstein, MD, MSc, ${ }^{10,11}$ and Aaron P. Thrift, $\mathrm{PhD}^{1,12}$

${ }^{1}$ Section of Epidemiology and Population Sciences, Department of Medicine, Baylor College of Medicine, Houston, Texas, USA

2Division of Gastroenterology and Hepatology, University of North Carolina School of Medicine, Chapel Hill, North Carolina, USA

${ }^{3}$ QIMR Berghofer Medical Research Institute, Brisbane, Queensland, Australia

${ }^{4}$ Centre for Public Health, Queen's University Belfast, Belfast, Northern Ireland

${ }^{5}$ Program in Epidemiology, Fred Hutchinson Cancer Research Center, Seattle, Washington, USA

${ }^{6}$ Division of Research, Kaiser Permanente Northern California, Oakland, CA, USA.

${ }^{7}$ San Francisco Medical Center, Kaiser Permanente Northern California, San Francisco, CA, USA.

${ }^{8}$ Section of Gastroenterology and Hepatology, Department of Medicine, Baylor College of Medicine, Houston, Texas, USA

${ }^{9}$ Center for Innovations in Quality, Effectiveness and Safety (IQuESt), Michael E DeBakey Veterans Affairs Medical Center, Houston, Texas, USA 
${ }^{10}$ Center for Clinical Management Research, Ann Arbor Veterans Affairs Medical Center, Ann Arbor, Michigan, USA

${ }^{11}$ Barrett's Esophagus Program, Division of Gastroenterology Department of Internal Medicine, University of Michigan Medical School, Ann Arbor, Michigan, USA

${ }^{12}$ Dan L Duncan Comprehensive Cancer Center, Baylor College of Medicine, Houston, Texas, USA

Abbreviations: BE, Barrett's esophagus; BEACON, Barrett's and Esophageal Adenocarcinoma Consortium; BMI, body mass index; $\mathrm{Cl}$, confidence interval; EAC, esophageal adenocarcinoma; GERD, gastroesophageal reflux disease; OR, odds ratio; WHR, waist-to-hip ratio.

Correspondence: Aaron P. Thrift, Ph.D., Dan L Duncan Comprehensive Cancer Center, Baylor College of Medicine, One Baylor Plaza, MS: BCM305, Houston, Texas 77030-3498. E-mail: aaron.thrift@bcm.edu

Key words: epidemiology; gastroesophageal reflux disease; risk factors.

Word count: 2684 


\section{Study Highlights}

\section{WHAT IS CURRENT KNOWLEDGE}

- Epidemiological studies have shown an inverse association between Helicobacter pylori infection and risk of esophageal adenocarcinoma.

- However, it remains unclear whether H. pylori is also inversely associated with the precursor lesion, Barrett's esophagus, and whether H. pylori is associated with Barrett's esophagus in the presence and/or absence of gastroesophageal reflux disease (GERD).

\section{WHAT IS NEW HERE}

- The findings from this large pooled analysis show that infection with $H$. pylori is associated with lower risk of Barrett's esophagus, particularly the CagA positive strain.

- $\quad$ This lower risk is probably mediated by a decrease in GERD in infected patients, since the protective effect disappears in populations who have GERD symptoms. 


\section{ABSTRACT}

OBJECTIVES: Epidemiological studies of Helicobacter pylori infection and risk of Barrett's esophagus (BE) have reported conflicting results. We examined the association between $H$. pylori infection and $\mathrm{BE}$ and sought to determine whether the association is mediated by gastroesophageal reflux disease (GERD) and to identify potential effect modifiers.

METHODS: We used individual level data from 1308 patients with BE (cases), 1388 populationbased controls, and 1775 GERD controls in the Barrett's and Esophageal Adenocarcinoma Consortium (BEACON). We estimated study-specific odds ratios (ORs) and 95\% Cls using multivariable logistic regression models and obtained summary risk estimates using a random effects meta-analytic approach. We examined potential effect modification by waist-to-hip ratio (WHR), body mass index (BMI), and smoking status by conducting stratified analyses.

RESULTS: For comparisons with population-based controls, H. pylori infection was inversely associated with the risk of $\mathrm{BE}$ (adjusted $\mathrm{OR}=0.44,95 \% \mathrm{Cl}=0.36-0.55$ ), with no evidence of between-study heterogeneity $\left(I^{2}=0 \%\right)$. A stronger inverse association between $H$. pylori and $\mathrm{BE}$ was observed among individuals with the CagA positive strain ( $P$ for interaction $=0.017)$. We found no evidence of interaction between WHR, BMI, smoking status and $H$. pylori infection on the risk of BE. There was no association between $H$. pylori infection and BE for comparisons with GERD controls $\left(\mathrm{OR}=0.96,95 \% \mathrm{Cl}=0.67-1.37 ; r^{2}=48 \%\right)$.

CONCLUSIONS: This study provides the strongest evidence yet that $H$. pylori infection is strongly inversely associated with BE. This effect is probably mediated by a decrease in GERD in infected patients, since the protective effect disappears in patients with GERD symptoms. 


\section{INTRODUCTION}

In the United States, 16,940 new cases of esophageal cancer and 15,690 deaths from esophageal cancer are expected to occur in $2017 .{ }^{1}$ While recent decades have witnessed a decline in the incidence of squamous cell carcinoma of the esophagus, ${ }^{2}$ a rising trend of esophageal adenocarcinoma (EAC) incidence has been observed in many developed countries. ${ }^{3}$ In the United States, the annual incidence of EAC has increased 9-fold since the early $1970 s^{4}$

Barrett's esophagus (BE), a condition in which the normal squamous mucosa of the esophagus is replaced by columnar intestinal epithelium, is the precursor lesion for EAC. ${ }^{5}$ Patients with $\mathrm{BE}$ have 10 - to 55 -fold higher risk of EAC than the general population. ${ }^{6}$ Since $B E$ is usually asymptomatic and remains clinically undetected, population-based studies have estimated a prevalence of $1.3-1.6 \%$ among general population, ${ }^{7,8}$ while clinic-based studies have estimated prevalence of $18.2 \%$ among patients undergoing endoscopy. ${ }^{9}$

Assessment of risk factors for BE allows for better understanding of disease pathophysiology and identification of new opportunities for disease prevention. Population-based case-control studies initiated in the past two decades have thus far consistently identified frequent symptoms of gastroesophageal reflux disease (GERD),${ }^{10}$ obesity, ${ }^{11}$ and possibly smoking ${ }^{12}$ as risk factors for BE. A potential protective factor for BE is infection with Helicobacter pylori. While H. pylori, especially the CagA positive (cytotoxin-associated gene product A-positive) strain, is a known strong risk factor for non-cardia gastric cancer (potentially accounting for $90 \%$ of cases worldwide each year),${ }^{13}$ the infection could decrease gastric acid production and subsequently reduce the likelihood of developing GERD, a major risk factor for BE. ${ }^{14}$ However, its role in reflux-induced esophageal injury and the effect of $H$. pylori eradication on GERD and reflux esophagitis continues to be debated. ${ }^{15} \mathrm{~A}$ meta-analysis of 49 observational studies examining 
the association between $H$. pylori infection and the risk of BE published through 2010 found an inverse association, but with considerable between-study heterogeneity ${ }^{16}$ potentially from choice of control group (e.g., population-based vs. clinical controls) and BE case definition (e.g., with and without intestinal metaplasia, or incident vs. prevalent cases). While population controls are sampled from underlying population where cases arose and are asymptomatic, clinical controls represent a symptomatic population undergoing endoscopy and are the ideal comparison group for assessing whether an association with BE is mediated by GERD. Furthermore, the small size of these individual studies has also limited the precision of resulting estimates of association and few studies had data on CagA positivity status. Most studies were unable to adequately control for confounding and it is unknown to what extent these associations vary by population using harmonized adjusted models. Finally, investigations of whether these associations differ with respect to known risk factors for BE (e.g., obesity and cigarette smoking) have been limited due to small numbers upon stratification.

To better understand this relationship, we assessed whether $H$. pylori infection is associated with the risk of $B E$ by pooling, harmonizing, and analyzing individual-level participant data from six case-control studies. We also sought to determine whether or not the association of $H$. pylori infection with $B E$ is mediated by GERD. 


\section{METHODS}

\section{Study population}

We analyzed individual-level participant data from the following six case-control studies in the international Barrett's and Esophageal Adenocarcinoma Consortium (BEACON, http://beacon.tlvnet.net/) that had available data on $H$. pylori infection status: the Houston Barrett's Esophagus study (based at the Michael E. DeBakey VA Medical Center at Houston, TX; hereafter "Houston"); ${ }^{17}$ the Factors Influencing the Barrett's/Adenocarcinoma Relationship study (based in Ireland; "FINBAR");18 the Epidemiology and Incidence of Barrett's Esophagus study (based in the Kaiser Permanente Northern California population; "KPNC"); ${ }^{19}$ The Newly Diagnosed Barrett's Esophagus Study (based at the University of Michigan and Ann Arbor Veterans Affairs Medical Center at Ann Arbor, MI; "NDB"); 9 the Study of Digestive Health (based in Brisbane, Australia; "SDH");20 and the Epidemiologic Case-Control Study of Barrett's Esophagus (Chapel Hill, NC; "UNC"). The NDB study included only males (cases and controls) ${ }^{9}$ and the UNC study only included BE cases and GERD controls. ${ }^{20}$ The Institutional Review Boards or Research Ethics Committees of each institution approved the acquisition and pooling of data for the present analysis. Participants provided written informed consent to take part in the studies.

In all studies, BE cases were persons with endoscopic evidence of columnar mucosa in the tubular esophagus and specialized intestinal metaplasia in an esophageal biopsy. We compared cases of BE with population-based controls, representing the underlying source population from which cases arose, and separately with GERD controls, representing the population undergoing endoscopy from which cases are diagnosed. GERD controls were participants who either were found to have erosive esophagitis on endoscopy or carried a clinician's diagnosis of GERD. Study-specific definitions for cases and controls are detailed in 
Supplementary Table 1. Owing to low numbers of cases from other ethnic groups, we restricted our analyses to non-Hispanic white study participants.

\section{Study variables}

The main exposure was $H$. pylori infection status (negative vs. positive), which was determined at each study center using assays blinded to case-control status running in mixed batches of cases and controls. The ELISAs applied in the individual studies has been validated in other ethnic groups. ${ }^{21-23}$ Cases and controls from FINBAR, KPNC and NDB studies were also tested for antibodies to the H. pylori CagA protein.

Potential confounding variables were available from all studies as part of a core dataset and were previously harmonized by the BEACON coordinating center. ${ }^{12,24-27}$ Variables selected $a$ priori as adjustment factors included age $(<50,50-<60,60-<70, \geq 70$ years), sex (except for NDB which included only males), highest level of education (school only, tech/diploma, university), cigarette smoking status (never, former, current), and body mass index (BMI; <25, 25-29.9, $\geq 30$ $\left.\mathrm{kg} / \mathrm{m}^{2}\right)$. In a subset of studies, we also pooled and harmonized data on patient's waist and hip measurements. Among participants with relevant data, a sensitivity analysis was also conducted to replace BMI in the model with waist-to-hip ratio (WHR) in quartile categorization to adjust for the effect of abdominal obesity instead of overall obesity.

\section{Statistical analysis}

Our primary analyses compared BE cases with population-based controls. We assessed the association between $H$. pylori infection and BE using a two-stage analytic approach. ${ }^{28}$ In the first stage, we used unconditional logistic regression models to estimate study-specific odds ratios (ORs) and 95\% confidence intervals (Cls). In the second stage, the study-specific ORs were pooled using random-effects meta-analytic models to generate a summary OR. We used the 
inconsistency index, $l^{2}$, and corresponding $p$-value to assess heterogeneity between studies. ${ }^{29}$ The $I^{2}$ statistic estimates the percentage of total variation across studies due to heterogeneity. An $l^{2}$ statistic of $0 \%$ indicates no heterogeneity that cannot be attributed to chance, whereas larger values indicate increasing heterogeneity beyond chance. ${ }^{29}$ We explored possible heterogeneity of the effect of $H$. pylori infection on risk of BE through analyses stratified by cigarette smoking status, BMI, and WHR (< median vs. $\geq$ median; median determined separately for each study). Potential interactions were assessed by fitting the interaction term between $H$. pylori infection status and the stratified variable into the model. Likelihood ratio tests of nested models with and without the interaction term were performed. To evaluate whether the virulent strain types of $H$. pylori could impact the effect of $H$. pylori on risk of BE, we further divided subjects into three groups: negative for $H$. pylori infection (reference group), positive for $H$. pylori infection with negative CagA antibody status; and positive for $H$. pylori infection with positive CagA antibody status. Finally, because the presence of $H$. pylori is thought to decrease gastric acid production and subsequently reduce the likelihood of developing GERD, we evaluated whether the association between $H$. pylori infection and BE was potentially mediated by GERD by comparing BE cases with GERD controls. To further verify an indirect pathway from $H$. pylori to BE through GERD, we also examined the association between $H$. pylori and GERD by comparing population-based controls with GERD controls. All analyses were conducted using SAS 9.4 (SAS Inc., Cary, NC, USA) and Cochrane review manager 5.3 (Cochrane, London, UK). Statistical significance was determined at $\alpha=0.05$, and all $p$-values for statistical significance were two-sided. 


\section{RESULTS}

We included data from 1308 BE cases, 1388 population-based controls and 1775 GERD controls. Across the six studies, $29.6 \%$ of population-based controls were $H$. pylori positive, while $17.2 \%$ of BE cases were $H$. pylori positive. However, the prevalence of $H$. pylori positive among controls (and cases) varied considerably across the six studies (Table 1). For example, prevalence of $H$. pylori positivity in population-based controls ranged from $18.9 \%$ in SDH to $62.1 \%$ in FINBAR; in GERD controls, from in $4.4 \%$ in UNC to $42.4 \%$ in FINBAR; in BE cases, from $5.2 \%$ in UNC to $43.3 \%$ in FINBAR.

In comparisons with population-based controls, we found an inverse association between $H$. pylori infection and BE. In the unadjusted analysis, infection with $H$. pylori was associated with $50 \%$ lower odds of $\mathrm{BE}$ (summary $\mathrm{OR}=0.50,95 \% \mathrm{Cl}=0.41-0.61, l^{2}=0 \%, p=0.88$ ). In models adjusted for age, sex, education, smoking status and BMI, $H$. pylori infection remained strongly inversely associated with $\mathrm{BE}$ (summary $\mathrm{OR}=0.44,95 \% \mathrm{Cl}=0.36-0.55 ; I^{2}=0 \%, p=0.63$ ) (Figure 1). As evidenced by the $I^{2}$ statistics, no heterogeneity was observed across the included studies. Sensitivity analysis showed no alteration of associations after replacing BMI in the model with WHR (summary OR=0.45, 95\% $\mathrm{Cl}=0.36-0.56 ; l^{2}=0 \%, p=0.52$ ) (Supplementary Figure 1).

We examined the association between $H$. pylori and BE within strata of known risk factors for BE (Table 2). We found consistently that $H$. pylori infection was inversely associated with BE across strata of smoking status $(p$-interaction $=0.867)$ and WHR ( $p$-interaction $=0.684)$. We found some evidence for a stronger inverse association with $H$. pylori infection among persons with normal BMI (summary OR=0.27, 95\% $\mathrm{Cl}=0.13-0.56$ ) than among overweight (summary $\mathrm{OR}=0.51,95 \% \mathrm{Cl}=0.36-0.71$ ) or obese (summary $\mathrm{OR}=0.47,95 \% \mathrm{Cl}=0.33-0.80$ ) persons, though the interaction term for $H$. pylori and BMI was not statistically significant $(p-$ interaction $=0.20)$. 
Further analysis was conducted to examine whether the inverse association differed by CagA (+/-) virulent strains of $H$. pylori infection (Table 3). By using the meta-analytical approach based on three studies (FINBAR, KPNC and NDB) with available CagA status information, the inverse association was somewhat stronger among subjects with CagA positive strain (summary $\mathrm{OR}=0.33,95 \% \mathrm{Cl}=0.21-0.53$ ) than those without (summary $\mathrm{OR}=0.56,95 \% \mathrm{Cl}=0.38-$ $0.82, p$-interaction $=0.017)$.

Finally, we examined for mediation by GERD by comparing BE cases with GERD controls. In the adjusted model, we found no association between $H$. pylori infection and the odds of BE (summary $\mathrm{OR}=0.96,95 \% \mathrm{Cl}=0.67-1.37, \mathrm{I}^{2}=48 \%, p=0.10$ ) (Figure 2). The existence of an indirect pathway from $H$. pylori infection to BE through GERD was further corroborated by the finding that $H$. pylori infection was strongly inversely associated with odds of GERD for comparisons of GERD controls with population-based control (summary OR=0.52, 95\% $\left.\mathrm{Cl}=0.35-0.78, l^{2}=69 \%, p=0.02\right)$ (Figure 3). 


\section{DISCUSSION}

In this large pooled analysis of individual-level participant data from six well-characterized casecontrol studies in BEACON, we found that $H$. pylori infection was associated with over $50 \%$ lower odds of BE. The magnitude of the inverse association was consistent across the included studies. In the stratified analyses, $H$. pylori infection was associated with lower odds of BE in all population sub-groups. However, we found no association between $H$. pylori infection and BE for comparisons with GERD controls, consistent with the hypothesis that the association between $H$. pylori infection and BE is mediated by GERD. Moreover, infection with more virulent strains provides increased protection against BE. While H. pylori infection decreases the risk of GERD in infected individuals, once a patient has GERD, there is no protection from BE associated with $H$. pylori.

Our understanding of the relationship between $H$. pylori infection and BE has been hampered by conflicting results from studies often too small to adequately address the issue and of varying design. While some studies reported lower risk of BE associated with $H$. pylori infection (using population-based controls, ${ }^{19,30}$ endoscopy-negative controls, ${ }^{17,31}$ or GERD controls ${ }^{32,33}$ ), there was no association in other studies..$^{34,35}$ The current analysis of individual-level participant data from studies participating in BEACON is much larger than any of these previous studies, and this larger sample size provided for greater statistical power and precision of risk estimates. Furthermore, the use of pooled and harmonized individual-level participant data provided more comparable statistical estimates than standard meta-analysis, which pool published ORs that differ in their variable definitions and the confounders included. In addition, the availability of both population-based controls and GERD controls allowed for comparisons with the underlying source population from which cases arose and the population undergoing endoscopy from which cases are diagnosed. Importantly, this also allowed us to examine whether $H$. pylori is associated with BE in the presence and/or absence of GERD; this is an important clinical 
question. Therefore, the results of this analysis are the strongest available data to date regarding the association between $H$. pylori and $\mathrm{BE}$.

$\mathrm{BE}$ is the recognized precursor lesion of EAC and, if $H$. pylori infection was association with risk of $\mathrm{BE}$, one can expect to observe an association between $H$. pylori infection and EAC as well. The results from population-based studies do provide strong evidence for an inverse association between $H$. pylori infection and EAC. ${ }^{18}$ Given the concordance of these data, associations between $H$. pylori infection and BE, as well as $H$. pylori infection and EAC, are likely to be real. The current results also provide strong evidence that $H$. pylori infection is associated with the risk of $\mathrm{BE}$ rather than risk of neoplastic progression in BE patients. In particular, we showed that H. pylori infection was strongly inversely associated with the risk of GERD. For symptomatic patients, there was no association between $H$. pylori infection and the risk of BE. Thus, the emphasis should be on managing GERD in these patients and not minimizing treatment efforts in H. pylori.

Our study has several notable strengths. First, the consortium approach enabled generation of the largest reported cohort of participants with $B E$ to date, upon which risk factor analysis has been performed. With over 1300 cases of $\mathrm{BE}$, we had greater power to detect associations, if present, and report more precise estimates of association with H. pylori infection than in any previous study. Furthermore, the large size of the pooled database enabled greater sample size and statistical power for stratified analyses and the assessment of potential interactions. Second, since BEACON applied standardized protocols in harmonizing data and deriving variables standardized across studies, using individual-level participant data allows for many benefits over meta-analysis of published estimates, including building consistent statistical models across studies and studying novel questions. Third, we found little evidence of between study heterogeneity, and the wide distribution of $H$. pylori prevalence across studies suggests 
our findings are generalizable to most settings. Fourth, the availability of both population-based controls and GERD controls allowed us to postulate where $H$. pylori infection might be active in the pathogenesis of $B E$. This is important because it is feasible that a significant proportion of the population-based control group might unknowingly have BE, although such misclassification would bias results toward the null.

Our study also has a number of limitations. First, observational studies are subject to bias. Although analyses of multiple variables provided little evidence of confounding, we cannot exclude incomplete control of confounding. Further, our results may be due to reverse causation whereby BE patients may had been previously treated for $H$. pylori infection in the more distant past, thereby decreasing their antibody titers. Second, the measurements of CagA status were only limited in three studies, decreasing the precision of these estimates, and ruling out the possibility of stratified analyses. Third, most of the six studies included a mix of patients with newly diagnosed and prevalent diagnoses of $\mathrm{BE}$, which could have biased the results unpredictably. Fourth, the absence of information on presence, distribution or severity of gastritis or gastric atrophy meant that we could not examine this factor as possible explanation. The Houston study previously found extent of gastritis as a possible explanation.

In summary, this pooled analysis found evidence for an inverse association between $H$. pylori infection and the odds of $\mathrm{BE}$, particularly the CagA positive strain. However, the association was mediated by GERD. H. pylori infection is not associated with BE among persons with GERD. 


\section{REFERENCES}

1. Siegel RL, Miller KD, Jemal A. Cancer Statistics, 2017. CA Cancer J Clin. 2017;67(1):7-30.

2. Abnet CC, Arnold M, Wei W-Q. Epidemiology of Esophageal Squamous Cell Carcinoma. Gastroenterology. August 2017. doi:10.1053/j.gastro.2017.08.023.

3. Thrift AP, Whiteman DC. The incidence of esophageal adenocarcinoma continues to rise: analysis of period and birth cohort effects on recent trends. Ann Oncol. 2012;23(12):31553162.

4. Vaughan TL, Fitzgerald RC. Precision prevention of oesophageal adenocarcinoma. Nat Rev Gastroenterol Hepatol. 2015;12(4):243-248.

5. Spechler SJ. Barrett's esophagus and esophageal adenocarcinoma: pathogenesis, diagnosis, and therapy. Med Clin North Am. 2002;86(6):1423-1445.

6. Cameron AJ, Ott BJ, Payne WS. The incidence of adenocarcinoma in columnar-lined (Barrett's) esophagus. N Engl J Med. 1985;313(14):857-859.

7. Zagari RM, Fuccio L, Wallander M-A, et al. Gastro-oesophageal reflux symptoms, oesophagitis and Barrett's oesophagus in the general population: the Loiano-Monghidoro study. Gut. 2008;57(10):1354-1359.

8. Ronkainen J, Aro P, Storskrubb T, et al. Prevalence of Barrett's esophagus in the general population: an endoscopic study. Gastroenterology. 2005;129(6):1825-1831.

9. Rubenstein JH, Inadomi JM, Scheiman J, et al. Association between Helicobacter pylori and Barrett's esophagus, erosive esophagitis, and gastroesophageal reflux symptoms. Clin Gastroenterol Hepatol Off Clin Pract J Am Gastroenterol Assoc. 2014;12(2):239-245.

10. Thrift AP, Kramer JR, Qureshi Z, Richardson PA, El-Serag HB. Age at onset of GERD symptoms predicts risk of Barrett's esophagus. Am J Gastroenterol. 2013;108(6):915-922.

11. Thrift AP, Shaheen NJ, Gammon MD, et al. Obesity and risk of esophageal adenocarcinoma and Barrett's esophagus: a Mendelian randomization study. J Natl Cancer Inst. 2014;106(11):dju252.

12. Cook MB, Shaheen NJ, Anderson LA, et al. Cigarette smoking increases risk of Barrett's esophagus: an analysis of the Barrett's and Esophageal Adenocarcinoma Consortium. Gastroenterology. 2012;142(4):744-753

13. Plummer M, Franceschi S, Vignat J, Forman D, de Martel C. Global burden of gastric cancer attributable to Helicobacter pylori. Int J Cancer. 2015;136(2):487-490.

14. Runge TM, Abrams JA, Shaheen NJ. Epidemiology of Barrett's Esophagus and Esophageal Adenocarcinoma. Gastroenterol Clin North Am. 2015;44(2):203-231.

15. Grande M, Lisi G, De Sanctis F, et al. Does a relationship still exist between gastroesophageal reflux and Helicobacter pylori in patients with reflux symptoms? World $\mathrm{J}$ Surg Oncol. 2014;12:375. 
16. Fischbach LA, Nordenstedt H, Kramer JR, et al. The association between Barrett's esophagus and Helicobacter pylori infection: a meta-analysis. Helicobacter. 2012;17(3):163-175.

17. Fischbach LA, Graham DY, Kramer JR, et al. Association between Helicobacter pylori and Barrett's esophagus: a case-control study. Am J Gastroenterol. 2014;109(3):357-368.

18. Anderson LA, Murphy SJ, Johnston BT, et al. Relationship between Helicobacter pylori infection and gastric atrophy and the stages of the oesophageal inflammation, metaplasia, adenocarcinoma sequence: results from the FINBAR case-control study. Gut. 2008;57(6):734-739.

19. Corley DA, Kubo A, Levin TR, et al. Helicobacter pylori infection and the risk of Barrett's oesophagus: a community-based study. Gut. 2008;57(6):727-733.

20. Thrift AP, Pandeya N, Smith KJ, et al. Helicobacter pylori infection and the risks of Barrett's oesophagus: a population-based case-control study. Int J Cancer. 2012;130(10):24072416.

23. Parsonnet J, Replogle M, Yang S, Hiatt R. Seroprevalence of CagA-positive strains among Helicobacter pylori-infected, healthy young adults. J Infect Dis. 1997;175(5):1240-1242.

24. Kendall BJ, Rubenstein JH, Cook MB, et al. Inverse Association Between Gluteofemoral Obesity and Risk of Barrett's Esophagus in a Pooled Analysis. Clin Gastroenterol Hepatol Off Clin Pract J Am Gastroenterol Assoc. 2016;14(10):1412-1419.

25. Kubo A, Cook MB, Shaheen NJ, et al. Sex-specific associations between body mass index, waist circumference and the risk of Barrett's oesophagus: a pooled analysis from the international BEACON consortium. Gut. 2013;62(12):1684-1691.

26. Thrift AP, Cook MB, Vaughan TL, et al. Alcohol and the risk of Barrett's esophagus: a pooled analysis from the International BEACON Consortium. Am J Gastroenterol. 2014;109(10):1586-1594.

27. Thrift AP, Anderson LA, Murray LJ, et al. Nonsteroidal Anti-Inflammatory Drug Use is Not Associated With Reduced Risk of Barrett's Esophagus. Am J Gastroenterol. 2016;111(11):1528-1535.

28. Smith-Warner SA, Spiegelman D, Ritz J, et al. Methods for pooling results of epidemiologic studies: the Pooling Project of Prospective Studies of Diet and Cancer. Am J Epidemiol. 2006;163(11):1053-1064.

29. Higgins JPT, Thompson SG, Deeks JJ, Altman DG. Measuring inconsistency in metaanalyses. BMJ. 2003;327(7414):557-560.

30. Rex DK, Cummings OW, Shaw M, et al. Screening for Barrett's esophagus in colonoscopy patients with and without heartburn. Gastroenterology. 2003;125(6):1670-1677.

31. Lam KD, Phan JT, Garcia RT, et al. Low proportion of Barrett's esophagus in Asian Americans. Am J Gastroenterol. 2008;103(7):1625-1630. 
32. Werdmuller BF, Loffeld RJ. Helicobacter pylori infection has no role in the pathogenesis of reflux esophagitis. Dig Dis Sci. 1997;42(1):103-105.

33. Monkemuller $\mathrm{K}$, Neumann $\mathrm{H}$, Nocon $\mathrm{M}$, et al. Serum gastrin and pepsinogens do not correlate with the different grades of severity of gastro-oesophageal reflux disease: a matched case-control study. Aliment Pharmacol Ther. 2008;28(4):491-496.

34. Peng S, Xiong L-S, Xiao Y-L, et al. Prompt upper endoscopy is an appropriate initial management in uninvestigated chinese patients with typical reflux symptoms. Am J Gastroenterol. 2010;105(9):1947-1952.

35. Rajendra S, Kutty K, Karim N. Ethnic differences in the prevalence of endoscopic esophagitis and Barrett's esophagus: the long and short of it all. Dig Dis Sci. 2004;49(2):237-242. 


\section{CONFLICT OF INTEREST}

Guarantor of the article: Aaron P. Thrift, Ph.D.

Specific author contributions: Z.W. and A.P.T. contributed to data analysis, interpretation of data and drafting of the manuscript. N.J.S, D.C.W, L.A.A., T.L.V., D.A.C., H.B.E-S., and J.H.R. designed, obtained funding and collected data from individual case-control studies, contributed to the concept of the consortium, interpretation of data and refinement of the manuscript. All authors approved the final draft submitted.

Financial support: This work was supported by the National Institutes of Health RO1 DK63616 (D.A.C.); 1R21DK077742 (N.J.S. and D.A.C.); K23DK59311 (N.J.S.); R03 DK75842 (N.J.S.); K23DK079291 (J.H.R.); R01 CA116845 (H.B.E-S.); K24-04-107 (H.B.E-S.); an Ireland-Northern Ireland cooperation research project grant sponsored by the Northern Ireland Research and Development Office and the Health Research Board, Ireland (FINBAR) (RES/1699/01N/S); the Study of Digestive Health, NCI RO1 CA 001833 (D.C.W.); the Established Investigator Award in Cancer Prevention and Control, K05 CA124911 (T.L.V.), and the US Department of Veterans Affairs CSRD Merit I01-CX000899 (J.H.R.); Z.W. is supported by a Research Training Grant from the Cancer Prevention and Research Institute of Texas (CPRIT; RP160097).

Potential competing interests: None. 


\section{Figure Legend}

Figure 1. Forest plot for the association between $H$. pylori infection and risk of Barrett's esophagus, compared with population-based controls. Odds ratios adjusted for age $(<50,50-59$, 60-69, $\geq 70$ years), sex (except NDB, all male), education (school only, tech/diploma, university), smoking status (never, former, current), and body mass index $(<25,25-29.3, \geq 30 \mathrm{~kg} / \mathrm{m} 2)$.

Figure 2. Forest plot for the association between H. pylori infection and risk of Barrett's esophagus, compared with GERD controls. Odds ratios adjusted for age $(<50,50-59,60-69$, $\geq 70$ years), sex (except NDB, all male), education (school only, tech/diploma, university), smoking status (never, former, current), and body mass index ( $<25,25-29.3$, $\geq 30 \mathrm{~kg} / \mathrm{m} 2)$.

Figure 3. Forest plot for the association between $H$. pylori infection and risk of GERD, compared with population-based controls. Odds ratios adjusted for age $(<50,50-59,60-69, \geq 70$ years), sex (except NDB, all male), education (school only, tech/diploma, university), smoking status (never, former, current), and body mass index (<25, 25-29.3, $\geq 30 \mathrm{~kg} / \mathrm{m} 2$ ).

Supplementary Figure 1. Forest plot for the association between $H$. pylori infection and odds of Barrett's esophagus, compared with population-based controls. Odds ratios adjusted for waist-to-hip ratio, compared with population-based controls. Odds ratios adjusted for age $(<50$, $50-59,60-69, \geq 70$ years), sex (except NDB, all male), education (school only, tech/diploma, university), smoking status (never, former, current), and waist-to-hip ratio (quartiles). 
Table 1. Characteristics of population-based controls, GERD controls and cases of Barrett's esophagus by study

\begin{tabular}{|c|c|c|c|}
\hline Characteristics & $\begin{array}{c}\text { Population-based } \\
\text { controls }\end{array}$ & $\begin{array}{l}\text { GERD } \\
\text { controls }\end{array}$ & $\begin{array}{c}\text { BE } \\
\text { cases }\end{array}$ \\
\hline Houston, $\mathbf{n}$ & 278 & 857 & 289 \\
\hline Age, mean (SD) & $62.7(6.3)$ & $60.4(8.7)$ & $61.6(7.4)$ \\
\hline Male, $\mathrm{n}(\%)$ & $273(98.2)$ & $778(90.8)$ & $282(97.6)$ \\
\hline Body mass index, mean (SD) & $31.2(6.3)$ & $30.1(6.0)$ & $30.2(5.5)$ \\
\hline Current smoker, n (\%) & $66(25.6)$ & $235(28.8)$ & $86(31.1)$ \\
\hline H. pylori positive, n (\%) & $77(27.7)$ & $204(23.8)$ & $53(18.3)$ \\
\hline FINBAR, $\mathbf{n}$ & 253 & 229 & 215 \\
\hline Age, mean (SD) & $62.7(12.8)$ & $61.3(11.4)$ & $62.1(11.9)$ \\
\hline Male, $\mathrm{n}(\%)$ & $214(84.6)$ & $188(82.1)$ & $180(83.7)$ \\
\hline Body mass index, mean (SD) & $27.8(3.9)$ & $29.2(4.0)$ & $27.9(4.3)$ \\
\hline Current smoker, n (\%) & $46(18.6)$ & $50(22.1)$ & $51(23.8)$ \\
\hline H. pylori positive, n (\%) & $157(62.1)$ & $97(42.4)$ & $93(43.3)$ \\
\hline KPNC, $\mathrm{n}$ & 248 & 241 & 254 \\
\hline Age, mean (SD) & $62.1(10.1)$ & $62.1(10.4)$ & $62.2(10.8)$ \\
\hline Male, n (\%) & $168(67.7)$ & $166(68.9)$ & $190(74.8)$ \\
\hline Body mass index, mean (SD) & $29.5(5.7)$ & $29.0(4.7)$ & $29.4(5.4)$ \\
\hline Current smoker, n (\%) & $31(12.5)$ & $23(9.5)$ & $34(13.4)$ \\
\hline H. pylori positive, n (\%) & $52(21.0)$ & $18(7.5)$ & $28(11.0)$ \\
\hline NDB, $n$ & 249 & 178 & 133 \\
\hline Age, mean (SD) & $59.7(6.9)$ & $57.1(6.1)$ & $61.3(6.9)$ \\
\hline Male, n (\%) & $249(100)$ & $178(100)$ & $133(100)$ \\
\hline Body mass index, mean (SD) & $30.1(5.8)$ & $29.9(5.5)$ & $30.5(5.0)$ \\
\hline Current smoker, n (\%) & $35(14.1)$ & $20(11.3)$ & $37(27.8)$ \\
\hline H. pylori positive, n (\%) & $57(22.9)$ & $25(14.0)$ & $18(13.5)$ \\
\hline SDH, $\mathbf{n}$ & 360 & 0 & 283 \\
\hline Age, mean (SD) & $59.8(10.7)$ & - & $60.0(11.4)$ \\
\hline Male, n (\%) & $233(64.7)$ & - & $201(71.0)$ \\
\hline Body mass index, mean (SD) & $27.1(4.8)$ & - & $27.6(4.7)$ \\
\hline Current smoker, n (\%) & $39(10.8)$ & - & $50(17.7)$ \\
\hline H. pylori positive, n (\%) & $68(18.9)$ & - & $26(9.2)$ \\
\hline UNC, $n$ & 0 & 270 & 134 \\
\hline Age, mean (SD) & - & $50.1(14.2)$ & $55.5(10.6)$ \\
\hline Male, $\mathrm{n}(\%)$ & - & $114(42.2)$ & $89(66.4)$ \\
\hline Body mass index, mean (SD) & - & $27.9(6.0)$ & $28.8(6.0)$ \\
\hline Current smoker, n (\%) & - & $40(14.8)$ & $20(14.9)$ \\
\hline H. pylori positive, $\mathrm{n}(\%)$ & - & $12(4.4)$ & $7(5.2)$ \\
\hline \multicolumn{4}{|c|}{$\begin{array}{l}\text { NOTE: Houston, the Houston Barrett's Esophagus study; FINBAR, the Factors Influencing the } \\
\text { Barrett's/Adenocarcinoma Relationship study (Ireland); KPNC, the Epidemiology and Incidence of Barrett's } \\
\text { Esophagus study (Kaiser Permanente, Northern California); NDB, The Newly Diagnosed Barrett's Esophagus } \\
\text { Study (University of Michigan and Ann Arbor Veterans Affairs Medical Center, Michigan); SDH, the Study of } \\
\text { Digestive Health (Brisbane, Australia); and UNC, the Epidemiologic Case-Control Study of Barrett's } \\
\text { Esophagus (Chapel Hill, North Carolina). Participants with missing data were excluded from \%s. }\end{array}$} \\
\hline
\end{tabular}


Table 2. ORs and 95\% Cls for the association between $\mathrm{H}$. pylori infection and odds of Barrett's esophagus, compared with population-based controls, stratified by smoking status, body mass index and waist-to-hip ratio

\begin{tabular}{|c|c|c|c|}
\hline Strata & $\begin{array}{c}\text { BE I } \\
\text { Population-based } \\
\text { controls }\end{array}$ & OR $(95 \% \mathrm{Cl})^{\mathrm{a}}$ & OR $(95 \% \mathrm{Cl})^{\mathrm{b}}$ \\
\hline \multicolumn{4}{|l|}{ Smoking status } \\
\hline Never smoker & $394 / 557$ & $\begin{array}{l}0.47(0.32-0.69) \\
\left(\left.\right|^{2}=0 \%, p=0.81\right)\end{array}$ & $\begin{array}{l}0.41(0.27-0.62) \\
\left(\left.\right|^{2}=0 \%, p=0.76\right)\end{array}$ \\
\hline Former smoker & $611 / 588$ & $\begin{array}{l}0.51(0.38-0.68) \\
\left(I^{2}=0 \%, p=0.93\right)\end{array}$ & $\begin{array}{l}0.46(0.34-0.63) \\
\left(I^{2}=0 \%, p=0.90\right)\end{array}$ \\
\hline Current smoker & $278 / 217$ & $\begin{array}{l}0.41(0.26-0.64) \\
\left(I^{2}=0 \%, p=0.81\right)\end{array}$ & $\begin{array}{l}0.36(0.21-0.59) \\
\left(I^{2}=0 \%, p=0.57\right)\end{array}$ \\
\hline \multicolumn{4}{|l|}{ Body mass index } \\
\hline $\mathrm{BMI}<25 \mathrm{~kg} / \mathrm{m}^{2}$ & $282 / 322$ & $\begin{array}{c}0.40(0.23-0.68) \\
\left(I^{2}=21 \%, p=0.28\right)\end{array}$ & $\begin{array}{c}0.27(0.13-0.56) \\
\left(I^{2}=43 \%, p=0.13\right)\end{array}$ \\
\hline BMI $25-29.9 \mathrm{~kg} / \mathrm{m}^{2}$ & $528 / 579$ & $\begin{array}{c}0.57(0.41-0.80) \\
\left(I^{2}=14 \%, p=0.33\right)\end{array}$ & $\begin{array}{l}0.51(0.36-0.71) \\
\left(I^{2}=0 \%, p=0.42\right)\end{array}$ \\
\hline $\mathrm{BMI} \geq 30 \mathrm{~kg} / \mathrm{m}^{2}$ & $487 / 475$ & $\begin{array}{l}0.50(0.36-0.71) \\
\left(I^{2}=0 \%, p=0.51\right)\end{array}$ & $\begin{array}{l}0.47(0.33-0.80) \\
\left(\left.\right|^{2}=0 \%, p=0.54\right)\end{array}$ \\
\hline \multicolumn{4}{|l|}{ Waist-to-hip ratio } \\
\hline Waist-to-hip ratio $<$ median & $477 / 697$ & $\begin{array}{l}0.50(0.37-0.67) \\
\left(I^{2}=0 \%, p=0.62\right)\end{array}$ & $\begin{array}{l}0.43(0.31-0.60) \\
\left(\left.\right|^{2}=0 \%, p=0.56\right)\end{array}$ \\
\hline Waist-to-hip ratio $\geq$ median & $606 / 646$ & $\begin{array}{l}0.52(0.39-0.69) \\
\left(I^{2}=0 \%, p=0.44\right)\end{array}$ & $\begin{array}{l}0.48(0.35-0.67) \\
\left(I^{2}=8 \%, p=0.36\right)\end{array}$ \\
\hline $\begin{array}{l}\mathrm{Cl} \text {, confidence interval; OR, odd } \\
\text { a Unadjusted model. } \\
\text { b Adjusted for age }(<50,50-59, \\
\text { tech/diploma, university), smoki } \\
\text { and body mass index (except w }\end{array}$ & stratified by $\mathrm{BMI} ;<25$ & $\begin{array}{l}\text { JDB, all male), educ } \\
\text { fied by smoking sta } \\
\left.9.3, \geq 30 \mathrm{~kg} / \mathrm{m}^{2}\right) \text {. }\end{array}$ & $\begin{array}{l}\text { chool only, } \\
\text { ver, former, current) }\end{array}$ \\
\hline
\end{tabular}


Table 3. ORs and 95\% Cls for the association between $H$. pylori infection and odds of Barrett's esophagus, compared with population-based controls

\begin{tabular}{llcc}
\hline $\begin{array}{c}\boldsymbol{H} . \text { pylori antibody } \\
\text { status }\end{array}$ & $\begin{array}{c}\text { CagA antibody } \\
\text { status }\end{array}$ & $\begin{array}{c}\text { BE I } \\
\text { Population-based controls }\end{array}$ & OR (95\% Cl) \\
\hline FINBAR & Negative & $122 / 96$ & 1.00 (ref.) \\
Negative & Negative & $15 / 20$ & $0.58(0.28-1.22)$ \\
Positive & Positive & $78 / 137$ & $0.40(0.26-0.60)$ \\
KPNC & Negative & $226 / 196$ & $1.00($ ref.) \\
Negative & Negative & $26 / 38$ & $0.51(0.29-0.89)$ \\
Positive & Positive & $2 / 14$ & $0.13(0.03-0.59)$ \\
& Negative & $115 / 192$ & $1.00($ ref. $)$ \\
NDB & Negative & $13 / 28$ & $0.63(0.30-1.32)$ \\
Negative & Positive & $5 / 29$ & $0.26(0.10-0.73)$ \\
Positive & & & $1.00($ ref. $)$ \\
Overall & Negative & $463 / 484$ & $0.56(0.38-0.82)$ \\
Negative & Negative & $54 / 86$ & $\left(I^{2}=0 \%, p=0.89\right)$ \\
Positive & & & $0.33(0.21-0.53)$ \\
& Positive & $85 / 180$ & $\left(I^{2}=11 \%, p=0.33\right)$ \\
\hline
\end{tabular}

CagA, cytotoxin-associated gene product $\mathrm{A}$

a Adjusted for age $(<50,50-59,60-69, \geq 70$ years), sex (except NDB, all male), education (school only,

tech/diploma, university), smoking status (never, former, current), and body mass index (<25, 25-29.3, $\geq 30$ $\mathrm{kg} / \mathrm{m}^{2}$ ). 